\title{
Transplantes cardiopulmonar e pulmonar com doador em localidade distante
}

\author{
Luis Sérgio FRAGOMENI*; Robert S. BONSER**; Michael P. KAYE**; Stuart W. JAMIESON**
}

RBCCV 44205-67

FRAGOMENI, L. S.; BONSER, R. S.; KAYE, M. P.; JAMIESON, S. W. - Transplantes cardiopulmonar e pulmonar com doador em localidade distante. Rev. Bras. Cir. Cardiovasc., 3(3): 196-200, 1988.

RESUMO: Em situaçōes especificas, os transplantes clinicos cardiopulmonar e pulmonar são, hoje, formas estabelecidas de tratamento para estágio final de doença cardiopulmonar e pulmonar. A obtenção de doadores adequados permanece o maior problema e a remoção de órgãos em localidades distantes é, hoje, uma necessidade. Embora muitos métodos de preservação pulmonar possam ser empregados para períodos isquêmicos de até 5 horas, a hipotermia e o uso de solução cardioplégica com infusão da soluçāo de Collins modificada no tronco pulmonar tem sido método simples e eficiente para preservaçâo do bloco coração-pulmão. Descrevemos, aqui, o método corrente que empregamos, com o qual os transplantes cardiopulmonar e pulmonar combinados foram sucedidos de excelente função cárdio-respiratória.

DESCRITORES: transplante cardiopulmonar; transplante cardiopulmonar, doadores; transplante pulmonar; transplante pulmonar, doadores.

\section{INTRODUÇĀO}

O transplante coração-pulmão é hoje uma opção terapêutica definida para pacientes em estágio final de doença cardiaca e pulmonar. Desde o início do programa de transplante coração-pulmão, estabelecido em 1981 na Universidade de Stanford ${ }^{10}$, "1, mais de 200 destes transplantes foram realizados em centros especializados em todo o mundo. Após maior experiência clínica adquirida com transplante cardiaco e cardiopulmonar, recentemente transplantes de pulmão isolado e de ambos os pulmōes têm sido reintroduzidos com sucesso em situaçōes clínicas específicas ${ }^{4}$. A falta de doadores, entretanto, permanece o principal fator limitante para a expansão dós programas e o atendimento do crescente número de pacientes. Esta dificuldade de obtenção de órgãos é principalmente evidente em relação ao tecido pulmonar. Embora todo doador disponivel seja primariamente avaliado para utilização de coração e pulmões, apenas $10 \%$ destes preencherão os critérios altamente estabelecidos para transplante combinado de coração e pul- mões ${ }^{7}$. Devido a esta dificuldade e a exemplo do transplante de coração isolado, tornou-se imprescindivel a expansão do raio de ação para a obtenção de órgãos, além dos doadores que possam ser deslocados ao mesmo hospital onde o receptador aguarda o transplante. Com o acúmulo da experiência clínica e o desenvolvimento de trabalho experimental paralelo, foram desenvolvidos métodos de preservação pulmonar permitindo adequada função respiratória após período isquêmico de 4-5 horas. Esses estudos permitiram a recente possibilidade de remover o bloco coração-pulmâo de doadores em locais distantes e subseqüente implante de pulmão associado ou isolado. Essa prática será decisiva para o incremento do número desses transplantes e aumentar as esperanças desse grupo especial de pacientes. Descrevemos, aqui, a técnica da simples infusāo pulmonar utilizada nos 2 últimos transplantes envolvendo tecido pulmonar, realizados na Universidade de Minnesota nos quais o tempo de isquemia do bloco coraçãopulmão foi, respectivamente, de 270 e 330 minutos.

Trabalho realizado no Minnesota Heart and Lung Institute. Minneapolis, Minnesota, USA.

Recebido para publicaçāo em 10 de outubro de 1988.

- Do Minnesota Heart and Lung Institute (Professor Convidado)

* Do Minnesota Heart and Lung Institute.

Endereço para separatas: Luis Sérgio Fragomeni. Rua Uruguai, 1555, Apt: 41. 96010 Passo Fundo, RS, Brasil. 
FRAGOMENI, L. S.; BONSER, R. S.; KAYE, M. P.; JAMIESON, S. W. - Transplantes cardiopulmonar e pulmonar com doador em localidade distante. Rev. Bras. Cir. Cardiovasc., 3(3): 196-200, 1988.

\section{TÉCNICA}

Independentemente da necessidade do receptor, se coração-pulmão, ou apenas pulmōes, a remoção dos órgãos do doador é realizada de forma semelhante, sendo o bloco coração-pulmão transportado para o hospital do receptor. Quando o objetivo é apenas o conjunto de pulmōes, com cuidadosa separaçāo, o coração poderá ser utilizado em outro paciente.

Usualmente, outras Unidades de Transplantes participam do mesmo procedimento, com subseqüente remoção do fígado, pâncreas e rins. O coração e os pulmões são inspecionados através de esternotomia mediana, com mobilização da veia inominada, aorta, veias cavas superior e inferior. O timo é removido e o pericárdio, ressecado até o nível das veias pulmonares, incluindo os nervos frênicos. A traquéia é exposta entre a veia cava superior (VCS) e a aorta ascendente. A veia azigos é mobilizada e seccionada entre ligaduras. Após dissecção completa dos órgãos a serem removidos, é administrada heparina intravenosa $(3 \mathrm{mg} / \mathrm{kg}$ ) e as cânulas para infusão das soluçōes são introduzidas, respectivamente, na artéria inominada e tronco pulmonar. Após heparinização, removem-se os cateteres venosos e de SwanGanz do coração direito, seguindo-se ligadura e divisão das veias inominada e cava superior. A veia cava inferior (VCI) é pinçada acima do diafragma, permitindo que o coração esvazie após 3 ou 4 batimentos. A aorta é pinçada distalmente à artéria inominada e solução cardioplégica $(1000 \mathrm{ml})$ é infundida nessa artéria. Inicia-se, então, a infusão no tronco pulmonar, com $60 \mathrm{ml} / \mathrm{kg}$ de solução de Collins modificada ( $65 \mathrm{ml}$ de glicose a $50 \%$ + $12 \mathrm{mEq}$ de $\mathrm{MgSo} 4$ adicionado para cada litro da solução, através de um rolete arterial isolado, num periodo de aproximadamente 4 minutos. A pressāo de infusāo no tronco pulmonar não deve exceder $20 \mathrm{mmHg}$. Uma vez iniciadas as infusões, a porta da aurícula esquerda é amputada e a $\mathrm{VCl}$, dividida acima da pinça, permitindo descompressão das cavidades direita e esquerda. Nesse momento, tanto o coração quanto os pulmões são esfriados com solução de Ringer a $4^{\circ} \mathrm{C}$, auxiliando, assim, na hipotermia. Nessa fase, o anestesista aplica ventilação manual com ar ambiente não aquecido. Após a infusāo das soluçōes, a aorta é seccionada distalmente à artéria inominada. A traquéia é mobilizada e, após aplicação dos grampos de auto-sutura (TA 55 stapling device $4,8 \mathrm{~mm}$ staples), seccionada $5 \mathrm{~cm}$ acima da carina, com os pulmōes mantidos em posição e parcialmente inflados (50\%). A remoção do bloco coração-pulmão é, então, completada com divisão das reflexōes pleurais e ligamentos pulmonares anteriores ao esôfago. Os órgẩos são transferidos para uma bolsa plástica estéril com solução de Ringer a $4^{\circ} \mathrm{C}$ e selada com outra bolsa semelhante. Assim protegidos, os órgãos são colocados em uma caixa com isolamento térmico e gelo e transportados para o hospital onde está o receptor.

Estando as funções miocárdicas e pulmonar diretamente relacionadas com o período isquêmico, é primor- dial que a comunicação entre as equipes cirúrgicas do receptor e do doador seja precisa. Sendo confirmada a viabilidade da utilização do coração e pulmōes através da observação intra-operatória, a cirurgia do receptor é iniciada. Após dissecção e mobilizaçāo inicial das estruturas a serem removidas, a remoção do bloco coração-pulmão é comandada pelo grupo do receptor. Quando se trata apenas de transplante cardíaco, a remoção do órgão doente só é efetuada quando o novo órgão está, efetivamente, na sala cirúrgica, já que esse procedimento pode ser completado em poucos minutos. Quando se trata de coração e pulmões, ou mesmo apenas pulmões, essa remoção é trabalhosa e demorada. Com o intuito de reduzir ao máximo o tempo de isquemia, a remoção dos órgãos do receptor é iniciada enquanto a equipe do doador está a caminho. Com o atual período isquêmico de 4 a 5 horas como limite-segurança, o risco adicional da possibilidade de problemas no transporte nāo pode, ainda, ser evitado.

O aspecto mais importante, em relação à cirurgia do receptor cardiopulmonar, é que o coração e os pulmões sejam removidos sem causar qualquer dano aos nervos frênico, vago e recurrente, e também promover absoluta hemostasia. Detalhes dessa técnica já foram anteriormente descritos ${ }^{9}$. O transplante de ambos os pulmōes foi baseado em trabalho experimental publicado pela Universidade de Toronto ${ }^{5,17}$ e também em nossos laboratórios ${ }^{3}$. Sumariamente, o coração é separado do espécime trazido pela equipe do doador, o qual poderá ser utilizado em outro receptor. A equipe do receptor, através de esternotomia mediana e já em circulação extracorpórea (CEC), terá promovido pneumectomia direita e esquerda. O átrio esquerdo do doador é anastomosado com o átrio esquerdo do receptor, seguido do tronco pulmonar e traquéia. A anastomose traqueal é, adicionalmente, protegida com epíploo pediculado trazido da cavidade abdominal.

No primeiro caso, o bloco coração-pulmão foi transplantado em menina com 8 anos de idade portadora de hipertensão arterial pulmonar primária. Os órgāos do doador foram removidos em hospital a $1700 \mathrm{~km}$ de distância, com um tempo isquêmico de 4 horas e meia. No segundo, o transplante de ambos os pulmões foi realizado em 1 paciente de 40 anos com deficiência de Alfa-1 antitripsina, no qual os órgãos implantados foram submetidos a uma isquemia de 5 horas e meia. Ambos evoluíram de maneira satisfatória no pós-operatório, com saturação de oxigênio adequada (paO2 > $100 \mathrm{mmHg}$ ) e $\mathrm{FiO} 2$ nunca superior a $35 \%$. Em ambas as situaçōes, o tubo endotraqueal foi removido no 2 : dia de pós-operatório, com boa oxigenaçāo arterial e suporte inotrópico usual nesses procedimentos. Antibióticos (Cephamandol e Nafcillin) e imunossupressão com ciclosporina A e azatioprina foram iniciados no pré-operatório, introduzindo prednisona duas semanas após o ato cirúrgico, com o intuito de prevenir complicaçōes com a anastomose traqueal. Esses pacientes obtiveram alta hospitalar em boa condição clínica, 3 semanas após 
FRAGOMENI, L. S.; BONSER, R. S.; KAYE, M. P.; JAMIESON, S. W. - Transplantes cardiopulmonar e pulmonar com doador em localidade distante. Rev. Bras. Cir. Cardiovasc., 3(3): 196-200, 1988.

o ato cirúrgico. As radiografias de tórax de ambos os pacientes são apresentadas nas Figuras 1 e 2.

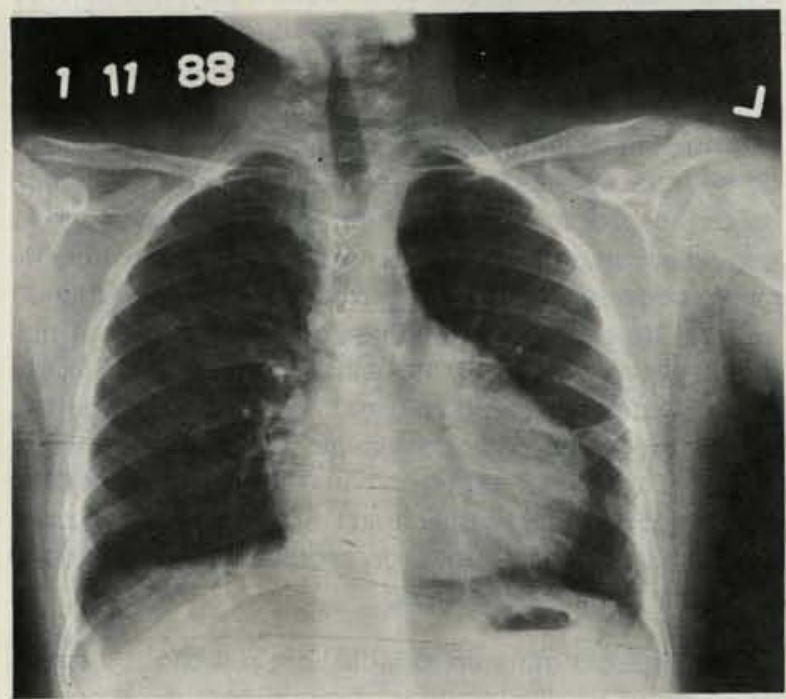

Fig. 1 - Controle pós-operatório, transplante cardiopulmonar. Paciente feminina, 8 anos, causa básica hipertensão pulmonar arterial

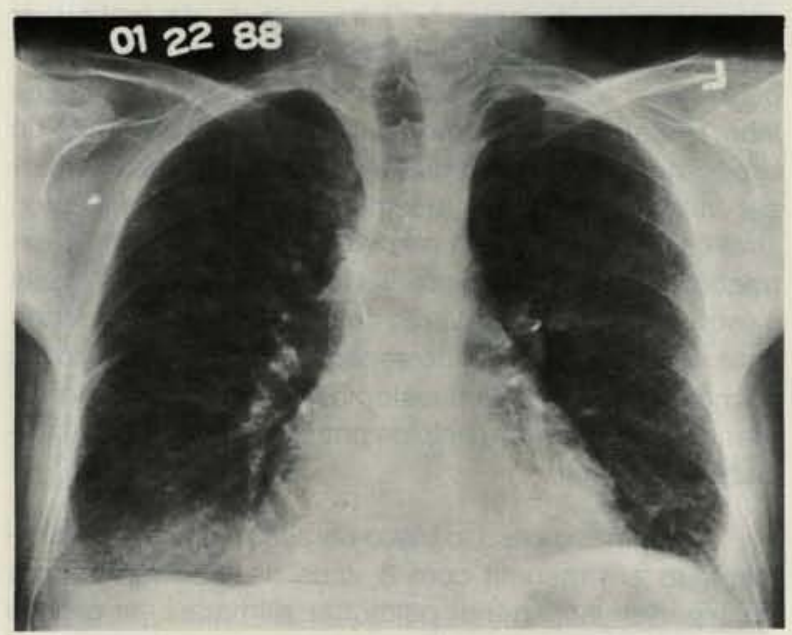

Fig. 2 - Controle pós-operatório, transplante pulmonar em bloco. Paciente masculino, 42 anos, causa básica deficiência de alfa 1 antitripsina.

\section{DISCUSSÃO}

O atual sucesso lançado no transplante de órgãos tem encontrado, como principal fator limitante, a falta de doadores. Os programas de transplante cardíacos são, hoje, basicamente dependentes da obtenção de órgãos em localidades distantes. Adequada proteção miocárdica através de cardioplegia e hipotermia nos permite isquemia miocárdica segura em torno de 4 horas e meia ${ }^{1}$. Estabelecida em Stanford, em meados de 1977, essa prática permite a remoção do coração de doadores num raio de, aproximadamente, $1600 \mathrm{~km}^{22}$. Entretanto, o parênquima pulmonar é mais sensível à lesão isquêmica ${ }^{8}$ e métodos adequados de proteção tecidual, seguida de isquemia prolongada, ainda não estão perfeitamente estabelecidos. Com o transplante de tecido pulmonar, fatores como denervação, completa perda da drenagem linfática e manipulação cirúrgica contribuem para o dano que se estabelece no período em que os pulmões estão desconectados da circulação ${ }^{12}$.

Diferentes métodos de preservação tecidual contra a lesão isquêmica e de reperfusão têm sido estudados em laboratório. Autoperfusão do bloco coração-pulmão utilizando a ação cardiaca como bomba de perfusão dos pulmōes, durante o intervalo do implante, tem demonstrado boa proteção do bloco coração-pulmāo. Ventilação traqueal é mantida e nutrientes intravenosos são necessários para manter o sistema. Embora tenha sido empregada com sucesso em algumas situaçōes clínicas, é complexa e não facilmente reproduzivel ${ }^{12,15}$. Esfriamento corpóreo total $\left(12^{\circ} \mathrm{C}\right) \mathrm{com}$ auxílio de CEC tem sido empregado com adequada oxigenação, após 4 horas de isquemia ${ }^{6,14}$. Entretanto, os fatores deletérios da CEC devem ser considerados, bem como a viabilidade prática de tal método, em determinados locais, sem as facilidades habituais de um centro cirúrgico desenvolvido. Experimentalmente, há relatos de boa oxigenação arterial após preservação pulmonar com infusāo de sangue gelado no tronco pulmonar do animal doador e posterior implante ${ }^{16}$. Entretanto, baseados em nossos experimentos (em fase de publicação), quando comparamos os resultados da preservação pulmonar através desse método com o de simples infusāo da soluçāo de Collins modificada, após 6 horas de isquemia, este último grupo demonstrou superior oxigenaçāo, nas 12 horas que se seguiram ao implante. Em nossa experiência e de outros, a simples infusão da "soluçāo de Collins modificada" no tronco pulmonar tem proporcionado adequada proteção pulmonar ${ }^{18,19}$. Essa solução, a mesma originalmente utilizada em alotransplante renal, é de composição intracelular e a adição de glicose hipertônica e sulfato de magnésio aumenta a osmolaridade e, melhor, preserva a integridade da membrana celular. A infusão de solução hipotérmica na árvore vascular pulmonar produz importante vasoconstrição arteriolar, o que, teoricamente, previne adequada distribuição do perfusato. $\mathrm{Na}$ tentativa de contrabalancear esse efeito, o grupo da Universidade de Stanford tem infundido prostaglandina E1 (PGE1) através de cateter venoso central na circulação do doador previamente à remoção dos órgāos ${ }^{2}$. Recentemente, estudamos o efeito da adição de PGE1 à solução de Collins com infusão no tronco pulmonar de cães em que realizamos autotransplante pulmonar unilateral. Através de toracotomia, o pulmão esquerdo é removido, seguido da infusão das soluções no tronco pulmonar e mantidos em refrigeraçăo por 4 horas, a uma temperatura de $4^{\circ} \mathrm{C}$. Após esse período, o pulmão é reimplantado, a artéria pulmonar contralateral, ligada e as funçōes respiratória e cardiovascular, monitorizadas por 6 horas. Comparado com o grupo em que administramos apenas a solução de Collins modificada, este demonstrou melhor 
FRAGOMENI, L. S.; BONSER, R. S.; KAYE, M. P.; JAMIESON, S. W. - Transplantes cardiopulmonar e pulmonar com doador em localidade distante. Rev. Bras. Cir. Cardiovasc., 3(3): 196-200, 1988.

oxigenação arterial pós-implante. Observamos, também, no grupo com PGE1, maior hiperemia pulmonar no periodo de reperfusão pós-isquemia e no final das primeiras 6 horas, o peso "seco" pulmonar foi discretamente superior ao controle. Prostaciclina tem, também, sido utilizada de maneira semelhante, em períodos moderados de isquemia $(85,70,101$ minutos), com bons resultados.

Nossa experiência atual tem demonstrado que é possivel obter-se boa preservação do bloco cardiopulmonar num período aproximado de 5 horas de isquemia. Observamos que, no transplante de ambos os pulmões, apesar do longo período isquêmico (5 horas e meia), a função respiratória após o transplante foi extremamente satisfatória. Concluímos que o fato do coraçẫo do receptor ser normal e ter sido submetido a um período isquêmico curto (pinçamento aórtico 32 minutos) foi fundamental para o suporte circulatório no pós-operatório imediato. Esta observação dá margem a um possivel período mais longo de isquemia pulmonar nos pacientes que não necessitam do transplante cardíaco associado. Com a experiência acumulada no transplante de ambos os pulmōes, certamente um grande número de pacientes com doença pulmonar, que, até recentemente, vinham sendo tratados com o transplante combinado de coração e pulmões, poderão ter apenas os pulmōes transplantados. Isto viabilizará uma utilização mais racional dos órgãos, além de permitir a remoção do tecido pulmonar em localidades mais distantes e subseqüentes periodos mais longos de isquemia. Nossa prática atual é a simples infusão da soluçấo de Collins modificada a $4^{\circ} \mathrm{C}$, cardioplegia e cuidadosa hipotermia adicional com banho de solução de Ringer a $4^{\circ} \mathrm{C}$. Com este método simples e facilmente reproduzivel em qualquer hospital, o bloco coração-pulmão pode ser removido em localidades distantes, com segurança. Contínua investigação no campo da preservação cardiopulmonar permitirá, em breve, extendermos o período isquêmico facilitando a utilização de doadores em outras localidades e viabilizarmos, assim, a realização de um maior número de transplantes.

\section{RBCCV 44205-67}

FRAGOMENI, L. S.; BONSER, R. S.; KAYE, M. P.; JAMIESON, S. W. - Distant donor procurement for heart-lung and lung transplantation. Rev. Bras. Cir. Cardiovasc., 3(3): 196-200, 1988.

ABSTRACT: In special situations, clinical heart-lung and lung transplantation are today established methods of therapy for end stage cardiopulmonary and pulmonary disease. Adequate donor availability remains a major problem and distant organ procurement is today a necessity. Although many methods of lung preservation can be used, for periods of up to 5 hours, hypothermic storage with cardioplegic arrest and pulmonary artery flush with modified Collins solution has proven to be a simple and reliable method of heart-lung preservation. We here describe our current method of heart-lung block protection, in which heart-lung and double lung transplantation were performed followed by excelent cardiac and pulmonary function.

DESCRIPTORS: cardiopulmonary transplantation, donors; cardiopulmonary transplantation; pulmonary transplantation, donors; pulmonary transplantation.

\section{REFERÊNCIAS BIBLIOGRÁFICAS}

1 ANDREONE, P. A.; OLIVARI, M. T.; RING, S. W. - Clinical considerations of cardiac transplantation: preoperative and postoperative evaluation. Radiol. Clin. N. Am., 25(2): 357-366, 1987.

2 BALDWIN, J. C.; FRIST, W. H.; STARKEY, T. D.; HARJULA, A.; STARNES, V. A.; STINSON, E. B.; OYER, P. E.; SHUMWAY, N. E. - Distant graft procurement for combined heart and lung transplantation using pulmonary artery flush and simple topical hypothermia for graft preservation. Ann. Thorac. Surg., 43(6): 670-673, 1987

3 BONSER, R. S.; FRAGOMENI, L. S.; KRIET, J. M.; KAYE, M. P.; JAMIESON, S. W. - Technique of clinical double lung transplantation. (No prelo, J. Heart Transpl.).
4 COOPER, J. D.; PEARSON, F. G.; PATTERSON, G. A.; TODD, T. R. J.; GINSBERG, R. J.; GOLDBERG, M.; DE MAJO, W. A. P. - Technique of successful lung transplantation in humans. J. Thorac. Cardiovasc. Surg., 93(2): 173-181, 1987.

5 DARK, J. H.; PATTERSON, G. A.; AL-JILAIHAWI, A. N.; HSU, H.; EGAN, T.; COOPER, J. D. - Experimental in bloc double lung transplantation. Ann. Thorac. Surg., 42(4): 394-398, 1986.

6 HARDESTY, R. L. \& GRIFFITH, B. P. - Procurement for combined heart-lung transplantation: bilateral thoracotomy with sternal transection, cardiopulmonary bypass and profound hypothermia. J. Thorac. Cardiovasc. Surg., 89(5): 795-799, 1985.

7 HARJULA, A.; BALDWIN, J. C.; STARNES, V. A.; STINSON, E. B.; OYER, P. E.; JAMIESON, S. W.; SHUM- 
FRAGOMENI, L. S.; BONSER, R. S.; KAYE, M. P.; JAMIESON, S. W. - Transplantes cardiopulmonar e pulmonar com doador em localidade distante. Rev. Bras. Cir. Cardiovasc., 3(3): 196-200, 1988.

WAY, N. E. - Proper donor selection for heart-lung transplantation: the Stanford experience. J. Thorac. Cardiovasc. Surg., 94(6): 874, 880, 1987.

8 HAVERICH, A.; SCOTT, W. C.; JAMIESON, S. W. Twenty years of lung preservation: a review. J. Heart Transpl. 4: 234-240, 1985

9 JAMIESON, S. W.; STINSON, E. B.; OYER, P. E.; BALDWIN, J. C.; SHUMWAY, N. E. - Operative technique for heart-lung transplantation. J. Thorac. Cardiovasc. Surg., 87(6): 930-935, 1984.

10 JAMIESON, S. W.; STINSON, E. R.; OYER, P. E.; REITZ, B. A.; BALDWIN, J.; MODRY, D.; DAWKINS, M. B.; THEODORE, J.; HUNT, S.; SHUMWAY, N. E. - Heartlung transplantation for irreversible pulmonary hypertension. Ann. Thorac. Surg., 38(6): 554-562, 1984.

11 JAMIESON, S. W.; REITZ, B. A.; OYER, P. E.; BILLINGHAM, M.; MODRY, D.; BALDWIN, J.; STINSON, E. B.; HUNT, S.; THEODORE, J.; BIEBER, C. P.; SHUMWAY, N. E. - Combined heart and lung transplantation. Lancet, 1(8334): 1130-1131, 1983.

12 JAMIESON, S. W. \& OGUNAIKE, H. O. - Cardiopulmonary transplantation. Surg. Clin. N. Am., 66(3): $491-501,1986$

13 JONES, K. D.; CAVAROCCHI, N.; HAKIM, M.; CORYPEARCE, R.; ENGLISH, T. A. A.; WALLWORK, J. A single flush technique for successful distant organ procurement in heart-lung transplantation. J. Heart Transpl., 4(6): 614, 1985.

14 KONTOS, G. J.; ADACHI, H.; BORKON, A. M.; CAMERON, D. E.; BAUMGARTNER, W. A.; HUTCHINS, G. M.; BRAWN, J.; REITZ, B. A. - A no-flush, core cooling technique for successful cardiopulmonary preservation in heart-lung transplantation. J. Thorac. Cardiovasc. Surg., 94(6): 836-842, 1987.

15 LADOWSKI, J. S.; KAPELANSKI, D. P.; TEODORI, M. F.; STEVENSON, W. C.; HARDESTY, R. L.; GRIFFITH, B. P. - Use of auto-perfusion for distant procure- ment of heart-lung allografts. J. Heart Transpl., 4: 330-333, 1985.

16 MODRY, D. L.; WALPOTH, B. W.; COHEN, R. G.; SEIFERT, E. C.; BLEESE, N. M.; WARNECKE, H.; BIEBER, C. P.; BILLINGHAM, M. E.; JAMIESON, S. W.: SHUMWAY, N. E. - Heart-lung preservation in the dog followed by lung transplantation: a new model for the assessment of lung preservation. J. Heart Transpl., 2: 287-298, 1983.

17 PATTERSON, G. A.; COOPER, J. D.; DARK, J. H.; JONES M. T. - Experimental and clinical double lung transplantation. J. Thorac. Cardiovasc. Surg., 95(1): 70-74, 1988

18 REICHART, B. A.; NOVITZKI, D.; COOPER, D. K.; CUNNINGHAM, M. S.; ROSE, A. G. - Successful orthotopic heart-lung transplantation in the baboon after 5 hours of cold ischemia with cardioplegia and Collins solution. J. Heart Transpl. 6(1): 15-22, 1987.

19. STARKEY, T. D.: SAKAKIBARA, N.; HAGBERG, R. C.; TAZELAAR, H. D.; BALDWIN, J. C.; JAMIESON, S W. - Successful 6 hour cardiopulmonary preservation with simple hypothermic crystalloid flush. J. Heart Transpl., 5(4): 291-297, 1986.

20 STUART, R. S.; BAUMGARTNER, W. A.; BORKON, A. M.; BULKLEY, G. B.; BRAWN, J. D.; DE LA MONTE, S. M.; HUTCHINS, G. M.; REITZ, B. A. - Five hour hypothermic lung preservation with oxigen-free radical scavengers. Transpl, Proc., 17: 1454-1456, 1985

21 TEODORI, M. F.; STEVENSON, W. C.; LADOWSKI, J. S.; KAPELANSKI, D. P.; GRIFFITH, B. P.; TRENTO, A.; BOROVETZ, H. S.; HARDESTY, R. L. - Autoperfusing heart-lung preparation for preservation in heartlung transplantation. Surg. Forum, 36(3): 311-313. 1985.

22 WATSON, D. C.; REITZ, B. A.; BAUMGARTNER, W. A.; RANEY, A. A.; OYER, P. E.; STINSON, E. B.; SHUMWAY, N. E. - Distant heart procurement for transplantation. Surgery, 86(1): 56-59, 1979. 